\title{
Pengaruh Kemampuan Komunikasi Pengajar Sekolah Menengah Atas (SMA) Dalam Meningkatkan Mutu Hasil Belajar Di Kabupaten Majene
}

\author{
Zulfikar Haswin ${ }^{1}$, Andi Alimuddin Unde ${ }^{2}$ \\ ${ }^{1}$ Program Pascasarjana Program Studi Ilmu Komunikasi, Universitas Hasanuddin \\ ${ }^{2}$ Program Studi Ilmu Komunikasi, Fakultas Ilmu Sosial dan Ilmu Politik Program \\ Pascasarjana, Universitas Hasanuddin \\ e-mail: ${ }^{1}$ fikarunyil.lpmpsulbar@gmail.com, ${ }^{2}$ undealimuddin@yahoo.co.id
}

\begin{abstract}
This research aims to find out the influence between communication skills of Senior High School Teachers (SMA) in improving student learning outcomes in Majene Regency. This research uses descriptive quantitative method using an instrument that is a questionnaire (written question) sourced from teaching staff at the Senior High School Level in the Majene Regency Area to obtain primary data. Secondary data in this study were obtained from the results of field documentation by researchers. The results showed that the improvement in communication skills of teachers is in line with the increase in the quality of student learning outcomes and has a close significance relationship between the two. Thus, the higher the Knowledge, Skill, and Motivation components of teacher communication skills will be directly proportional to the quality of student learning outcomes and have a positive and strong influence.
\end{abstract}

\section{Keywords: Teacher Communication Ability, Knowledge, Skill, Motivation, Learning Outcomes, Students}

\begin{abstract}
Abstrak
Penelitian ini dilaksanakan dengan tujuan untuk mengetahui pengaruh antara kemampuan komunikasi Pengajar Jenjang Sekolah Menegah Atas (SMA) dalam meningkatkan hasil belajar siswa di Kabupaten Majene. Dalam penelitian ini digunakan metode kuantitatif deskriptif dengan menggunakan instrumen yaitu kuesioner (pertanyaan tertulis) yang bersumber tenaga pengajar pada Jenjang Sekolah Menengah Atas di Wilayah Kabupaten Majene untuk mendapatkan data primer. Data sekunder dalam penelitian ini didapatkan dari hasil dokumentasi lapangan oleh peneliti. Hasil penelitian menunjukkan meningkatnya kemampuan komunikasi pengajar akan selaras dengan peningkatan kualitas hasil belajar siswanya serta memiliki hubungan signifikasi yang erat diantara keduanya, sehingga dapat diartikan bahwa semakin tinggi komponen Knowledge, Skill, dan Motivasi pada kemampuan komunikasi pengajar akan berbanding lurus dengan kulitas hasil belajar siswa serta memberikan pengaruh yang positif dan kuat.
\end{abstract}




\section{Kata kunci: Komunikasi, Kemampuan Komunikasi Pengajar, Knowledge, Skill, Motivasi, Hasil Belajar, Pengajar, Siswa, Belajar.}

\section{A. Pendahuluan}

Permasalahan pendidikan adalah sebuah masalah yang terpenting bagi suatu bangsa, dapat pula dikatakan bahwa pendidikan merupakan persoalan yang vital bagi kehidupan sebuah bangsa. Lewat dunia pendidikanlah sumberdayasumberdaya manusia di tempa dan dipersiapkan untuk membangun dan memajukan bangsanya. Secara umum, pendidikan sendiri dapat diartikan sebagai upaya untuk membangun dan mengembangkan kualitas sumberdaya manusia agar memiliki keunggulan dan kompetensi yang memadai untuk kepentingan pembangunan bangsa dan negara. Penjelasan secara umum tentang pendidikan di atas lebih menguatkan bahwa memang pendidikan merupakan hal utama bagi sebuah negara.

Salah satu yang menjadi faktor yang penting untuk diperhatikan dalam keseharian disekolah-sekolah adalah, apakah komunikasi antara pengajar dan siswa dalam ruang belajar berjalan dengan baik. Berkomunikasi merupakah aktivitas yang tidak bisa kita hindari dalam keseharian kita, tanpa melakukan aktivitas yang satu ini hidup kita akan terasa kesepian dan hampa serta akan kita akan tertinggal dalam berbagai bidang. Oleh karena itu, aktivitas komunikasi adalah aktivitas yang sudah sangat lazim dan biasa kita lakukan dalam keseharian kita. Walaupun telah menjadi bagian dari aktivitas keseharian kita, namun dalam pengaplikasiannya masih banyak orang yang tidak berfikir dan belajar bagaimana menjadikan komunikasi mereka menyenangkan, berkesan, dan yang paling penting adalah bagaimana maksud pesan dari tersebut di pahami, di mengerti oleh lawan berkomunikasi kita.

Adanya ketidakmampuan komunikasi yang baik dan efektif dari pengajar dalam memberikan materi di depan kelas menyebabkan materi yang disampaikan di depan kelas walaupun telah dikuasai dengan baik dan menggunkan metode 
yang telah dipersiapkan menjadi tumpul dan tidak terserap dengan baik oleh peserta didik. (Ria et al., 2020). Untuk itu, kompetensi komunikasi dari seorang pengajar yang mumpuni akan menghasilkan sebuah proses belajar mengajar yang efektif ditandai dengan meningkatnya hasil belajar siswa.

Dalam buku Barbara-Brown dengan judul What is effective communication (2016:23) dinyatakan bahwa indikator untuk sebuah komunikasi yang efektif ditandai dengan kejelasan, perkataan langsung, dan aktif mendengar. Komunikasi yang berjalan efektif sangat berguna dalam mempengaruhi, membujuk, dan menghibur sesuai tujuan komunikasi (Hasyim et al., 2020) Dengan adanya kompetensi komunikasi pengajar yang memadai akan mengefektifkan berjalannya komunikasi di dalam kelas sehingga akan menciptakan sebuah suasana belajar mengajar yang menarik, efektif dan menyenangkan yang akan membuat para peserta didik terubah pengetahuannya, paradigmanya, terlebih akan mengubah tingkah lakunya serta akan tercipta saling pengertian yang mendalam antara pengajar sebagai komunikator dan siswa sebagai komunikan.

Akan lebih baik jika para siswa dapat berkomunikasi denga semua pengajar dengan baik dan efektif tanpa terkecuali, sehingga sebagai seorang pengajar diwajibkan berperan aktif dalam menciptakan rasa nyaman dan keterbukaan ketika berkomunikasi dengan para peserta didik, sehingga akan menjadi sebuah tantangan untuk mengetahui pengaruh kemampuan komunikasi pengajar terhadap peningkatan kualitas hasil belajar siswa.

\section{B. Metode Penelitian}

Dalam penelitian ini digunakan metode dapat diartikan sebagai metode penelitian yang digunakan untuk meneliti pada populasi atau sampel tertentu, teknik pengambilan sampel dilakukan dengan sampel jenuh, pengumpulan data menggunakan instrument penelitian, serta bersifat statistik pada analisis datanya dengan tujuan untuk melakukan pengujian terhadap hipotesis yang telah ditentukan secara kuantitatif (sugiyono, 2016, Saputra, et al., 2020, Hasyim, et at., 2020). 
Penelitian ini mengambil lokasi Sekolah Menengah Atas (SMA) di wilayah pusat kota Kabupaten Majene yaitu pada SMA Negeri 2 Majene dan SMA Negeri 3 Majene, serta SMA Negeri 1 Pamboang dikarenakan sekolah ini merupakan sekolah favorit dengan prasarana yang cukup lengkap serta memiliki lingkungan belajar yang kondusif, serta dalam setiap kegiatan olympiade sains tingkat Kabupaten Majene kedua sekolah ini yang memiliki utusan yang lolos ke tingkat provinsi.

Seluruh pengajar dari 3 (Tiga) sekolah yang telah dipilih sebagai populasi dalam penelitian ini merupakan sampel yang akan digunakan. Metode sampling dengan menggunakan sampel jenuh (sensus) kami gunakan karena jumlah sampel hanya 100 orang berdasarkan data dari jumlah pengajar kelas XI dan XII dari ke tiga sekolah tersebut. Data yang terkumpul selanjutnya dideskripsikan lalu di analisis dan diinterpretasikan.

\section{Hasil dan Pembahasan}

Berdasarkan hasil analisis data dengan menggunakan IBM SPPS versi 23, maka pada bagian ini peneliti akan menguraikan hasil penelitian yang menjadi jawaban dari permasalahan yaitu sebagai berikut :

\section{C.1. Pengaruh Kemampuan Komunikasi Guru dengan Hasil Kualitas Belajar}

Dari hasil pengujian dengan menggunakan aplikasi IBM SPPS Versi 23, melalui uji simultan didapatkan hasil bahwa Dengan nilai Signifikasi sebesar $0,000<$ alpha $(0,05)$ maka dapat ditarik simpulan bahwa $\mathrm{H} 0$ dinyatakan di tolak dan H1 diterima sehingga diartikan terdapat pengaruh secara simultan yang signifikan pada kemampuan komunikasi pengajar terhadap kualitas hasil belajar siswa pada jenjang SMA di Kabupaten Majene. Ketika kita merujuk pada pendapat Brian Spitzberg dan William Cupach (dalam Greene dan Burleson : 2003; Payne : 2005), dimana menurut mereka terdapat 3 (Tiga) komponen dalam kompetensi komunikasi dimana menurut mereka komponen komunikasi itu 
adalah Knowledge, Skills, dan Motivation. Berdasarkan pendapat di atas dalam penelitian ini kami menggunakan komponen kompetensi komunikasi tersebut.

\section{C.2. Pengaruh Variabel Knowledge terhadap Kualitas Hasil Belajar Siswa}

Knowledge dalam kemampuan komunikasi pengajar merupakan variabel penting sehingga proses komunikasi dalam belajar mengajar dapat berjalan efektif dan efisien. Pengetahuan ini berupa pengetahuan tentang bagaimana tingkah laku yang akan diambil dalam berkomunikasi, seperti apa perkataan yang harus diucapkan, mengetahui dengan siapa kita berkomunikasi, serta memahami isi pesan yang dikomunikasikan. Hal ini tentu saja sejalan dengan pendapat Spitzberg dan Cupach (dalam Greene dan Burleson : 2003; Payne : 2005) yang menyatakan bahwa dalam hal berkomunikasi, pengetahuan ditekankan pada "Bagaimana" sebenarnya berkomunikasi, bukan pada "Apa" sebenarnya komunikasi itu. Sehingga dapat dikatakan jika seorang pengajar memiliki pengetahuan berkomunikasi yang baik dapat dipastikan kemampuan berkomunikasinya juga akan baik.

Dengan melakukan uji parsial terhadap komponen pengetahuan ini diperoleh nilai signifikan dari knowledge $0,000<$ alpha $(0,05)$ sehingga dapat disimpulkan bahwa H0 di tolak dan H1 diterima. Kondisi ini dapat diartikan bahwa terdapat pengaruh yang signifikan untuk komponen knowledge terhadap kualitas hasil belajar siswa pada jenjang SMA Di Kabupaten Majene. Jika kita merujuk kepada teori belajar konstruksivisme, Peran pengajar menurut teori ini adalah membantu peserta didiknya sehingga proses pengkonstruksian pengetahuan berjalan dengan lancar. Dalam hal ini pengajar diwajibkan untuk mengerti cara pandang belajar para peserta didik. Proses mengerti cara pandang belajar peserta didik ini adalah bentuk dari pengetahuan pengajar yang merupakan aplikasi dari indikator kompenen kemampuan pedagogik berdasarkan Permendiknas No 16 tahun 2007.

Merujuk pada jawaban kuesioner yang telah di isi oleh 96 responden Komponen pengatahuan atau knowledge berada pada kategori tinggi dan hal ini 
berbanding lurus pada nilai hasil belajar siswa ketika di tinjau dari nilai Ujian Sekolah Berstandar Nasional (USBN) dan Nilai E-Raport. Sehingga dapat disimpulkan bahwa semakin tinggi komponen pengetahuan pada kemampuan komunikasi pengajar akan berbanding lurus dengan kulitas hasil belajar siswa serta memberikan pengaruh yang signifikan.

\section{C.3. Pengaruh Variabel Skill terhadap Kualitas Hasil Belajar Siswa}

Dalam kemampuan komunikasi pengajar Skill yang merupakan aksi nyata dalam sebuah perilaku dapat diartikan sebagai kemampuan individu mengolah tingkah laku dalam melakukan komunikasi. Dalam teori belajar kontruksivisme kemampuan skill dari pengajar merupakan hal yang penting sebab dalam perannya sebagai mediator pengajar hendaknya menghadirkan kualitas lingkungan yang interaktif, mengelola arus kegiatan peserta didik, menampung permasalahan yang diajukan peserta didik dan mengembalikan lagi permasalahan tersebut kepada peserta didik yang lain untuk dijawab dan dipecahkan, lalu pengajar bersama peserat didik membuat sebuah kesimpulan atas jawaban dari permasalahan tersebut sebagai hasil belajar. Hal ini sejalan dengan pendapat Winarno Surachmad dalam Cepi Triatna (2007) yang menyatakan bahwa Pengajar sebagai mediator yang diartikan sebagai perantara dalam usaha untuk mendapatkan perubahan tingkah laku siswa.

Kemampuan komunikasi pengajar untuk komponen Skill ini dimaksudkan bahwa pengajar wajib memiliki keahlian dalam membawakan pelajaran di depan kelas agar proses pemahaman ilmu dalam proses belajar mengajar sesuai yang diharapkan sehingga hasil belajar siswa dapat ditingkatkan.

Dengan melakukan uji parsial terhadap komponen Skill ini diperoleh nilai signifikan dari knowledge $0,000<$ alpha $(0,05)$ sehingga dapat di buat simpulan bahwa H0 di tolak dan H1 diterima. Kondisi ini dapat diartikan bahwa terdapat pengaruh yang signifikan untuk komponen Skill terhadap kualitas hasil belajar siswa pada jenjang SMA Di Kabupaten Majene.

Merujuk pada jawaban kuesioner yang telah di isi oleh 96 responden 
Komponen Skill berada pada kategori tinggi dan hal ini berbanding lurus pada nilai hasil belajar siswa ketika di tinjau dari nilai Ujian Sekolah Berstandar Nasional (USBN) dan Nilai E-Raport. Sehingga dapat disimpulkan bahwa semakin tinggi komponen Skill pada kemampuan komunikasi pengajar akan berbanding lurus dengan kulitas hasil belajar siswa serta memberikan pengaruh yang signifikan.

\section{C.4. Pengaruh Variabel Knowledge terhadap Kualitas Hasil Belajar Siswa}

Dalam proses belajar mengajar selain pengajar harus memiliki pengetahuan dan skill yang baik hal yang tak bisa disepelekan juga adalah motivasi. Komponen Motivasi yang didefenisikan sebagai sebuah hasrat untuk melakukan komunikasi adalah variabel penting dalam kemampuan komunikasi pengajar. Hal ini sejalan dengan pendapat Sugihartono, dkk. (2007: 76-77) menjelaskan faktor psikilogis merupakan faktor yang dapat mempengaruhi hasil belajar. Faktor psikologis ini tidak dapat dipisahkan dengan motivasi semakin besar motivasi dalam proses belajar mengajar akan memberikan pengaruh positif terhadap psikologis peserta didik.

Sejalan dengan pergeseran makna proses belajar mengajar dari belajar mengajar yang berpusat kepada pengajar (teacher oriented) ke belajar mengajar yang berpusat kepada siswa (student oriented) yang tak lain adalah penerapan dari teori belajar Kontruksivisme, maka peran pengajar dalam proses belajar mengajar pun mengalami pergeseran, salah satunya adalah penguatan peran pengajar sebagai motivator.

Proses belajar mengajar akan berhasil manakala siswa mempunyai motivasi dalam belajar. Oleh sebab itu, pengajar perlu menumbuhkan motivasi belajar siswa. Untuk memperoleh hasil belajar yang optimal, pengajar dituntut kreatif membangkitkan motivasi belajar siswa, sehingga terbentuk perilaku belajar siswa yang efektif. Hal ini sejalan dengan pendapat Brian Spitzberg dan William Cupach (dalam Greene dan Burleson : 2003; Payne : 2005) yang menyatakan bahwa semakin seorang memiliki motivasi yang tinggi dalam dirinya untuk 
melakukan komunikasi, maka akan semakin besar pula kemauannya untuk berkomunikasi efektif dan meninggalkan kesan yang baik terhadap lawan berkomunikasinya.

Dengan melakukan uji parsial terhadap komponen Motivation nilai signifikan dari knowledge $0,044<$ alpha $(0,05)$ sehingga dapat disimpulkan bahwa H0 di tolak dan H1 diterima. Kondisi ini dapat diartikan bahwa terdapat pengaruh yang signifikan untuk komponen Skill terhadap kualitas hasil belajar siswa pada jenjang SMA Di Kabupaten Majene.

Merujuk pada jawaban kuesioner yang telah di isi oleh 96 responden Komponen Motivasi berada pada kategori tinggi dan hal ini berbanding lurus pada nilai hasil belajar siswa ketika di tinjau dari nilai Ujian Sekolah Berstandar Nasional (USBN) dan Nilai E-Raport. Sehingga dapat disimpulkan bahwa semakin tinggi komponen motivasi pada kemampuan komunikasi pengajar akan berbanding lurus dengan kulitas hasil belajar siswa serta memberikan pengaruh yang signifikan yang kuat.

\section{Penutup}

Berdasarkan hasil penelitian dan pembahasan yang telah diuraikan di atas, maka kesimpulan yang dapat di ambil dari penelitian ini adalah Kemampuan Komunikasi pengajar Di Kabupaten Majene berdasarkan hasil penelitian di lapangan berada pada level kategori tinggi. Kondisi ini menggambarkan bahwa pengajar memiliki kemampuan untuk membawakan materi ajar di depan kelas dan mampu mengolah proses belajar mengajar serta menciptakan kondisi belajar yang efektik dan menyenangkan untuk meningkatkan kualitas hasil belajar siswanya.

Kemampuan komunikasi pengajar yang terbagi dalam tiga komponen yaitu Knowledge, Skill, dan Motivasi secara simultan memberikan pengaruh postitif dengan signifikasi yang kuat terhadap peningkatan kualitas belajar siswa pada jenjang SMA di Kabupaten Majene. Hal ini juga selaras ketika komponen tersebut diuji secara parsial hasilnya pun menunjukkan pengaruh positif dengan signifikasi yang kuat. Sehingga dapat disimpulkan bahwa kemampuan komunikasi pengajar pada Jenjang SMA berpengaruh positif terhadap peningkatan kualitas hasil belajar 
siswa di Kabupaten Majene.

Ucapan terima kasihUcapan terima kasih dan rasa syukur kepada Tuhan Yang Maha Esa atas limpahan rahmat-Nya, Ucapan terima kasih yang tiada terkata atas dukungan kedua orang tua tercinta, Istri, serta adik-adik ku, Ucapan terima kasih yang begitu besar kepada Prof. Dr. Alimuddin Unde Selaku Pembimbing I pada Penelitian ini dan kepada Dr. Tuti Bahfiarti, S,Sos, M.Si selaku pembimbing II, Terima Kasih Kepada Bapak Sinar Alam S.Pd,M.Pd selaku Kepala LPMP Sulawesi Barat tempat kami bertugas, Terima kasih kepada Bapak Parenta, M.Hum atas bimbingan dan masukannya, Terima Kasih Kepada Bapak Dr. Muhammad Hasyim atas bantuan yang begitu besar, rekan-rekan Feedback ilmu komunikasi angkatan 2018 Ganjil, Civitas SMA Negeri 2 Majene, SMA Negeri 2 Majene, dan SMA Negeri 1 Pamboang serta semua yang mendukung tanpa terkecuali.

\section{Referensi}

Abbas, Hafid. (2019). Meluruskan Arah Pendidikan, Isu-Isu Kritis Pendidikan . Jakarta: Kompas Media Nusantara.

Akdon, dan Riduan. (2013). Rumus dan Data Dalam Analisis Statistika . Bandung: Alfa Beta.

Arikunto, Suharsimi. (1993). Manajemen Penelitian . Jakarta: Raja Grafindo Persada.

Cangara, Hafied (2012). Pengantar Ilmu Komunikasi. Jakarta: Raja Grafindo Perkasa

Departemen Pendidikan Nasional. (2003). Undang-Undang Nomor 20 Tahun 2003, Tentang Sistem Pendidikan Nasional. Jakarta: Depdiknas

Departemen Pendidikan Nasional. (2005). Undang-Undang Nomor 14 Tahun 2005, Tentang Pengajar dan Dosen. Jakarta: Depdiknas

Devito, J. A. (2018). Komunikasi Antar Manusia. Jakarta: Karisma Publishing 
Group.

Effendy, Onong Uchjana. (2007). Ilmu Komunikasi, Toeri dan Praktek. Bandung:

PT. Remaja Rosdakarya.

Hasyim, M., Kuswarini, P., \& Kaharuddin. (2020). Semiotic Model for

Equivalence and Non-Equivalence In Translation, Humanities \& Social

Sciences Reviews, 8, (3), 381-391.

Hasyim, M., Nursidah,\& Hasjim, M., (2019). Online advertising: how the consumer goods speaks to women. Opcion. Vol. 35 (89), 826-845.

Moleong, Lexy J. (2007). Metodologi Penelitian Kualitatif. Bandung: PT. Remaja Rosdakarya.

Muhammad, Ami. (2014). Komunikasi Organisasi. Jakarta: Bumi Aksara.

Mulyana, Deddy. (2008). Komunikasi Efektif, Suatu Pendekatan Lintas Budaya. Bandung: PT. Remaja Rosdakarya.

Muhammad Irham, Novan Ardy Wiyani. (2013). Psikologi Pendidikan, Teori dan Aplikasi dalam Proses Pembelajara. Yogyakarta: Ar-Ruzz Media.

Naim, Ngainun (2011). Dasar-Dasar Komunikasi Pendidikan. Yogyakarta: ArRuzz Media.

Nana Sudjana (2005). Dasar-Dasar Proses Belajar Mengajar. Bandung: Sinar Baru Algesindo.

Nofrion (2018). Komunikasi Pendidikan, Penerapan Teori dan Konsep dalam Belajar mengajar. Jakarta: Kencana.

Payne, H.J. (2005). Reconceptualizing Social Skill in Organization : Exploring The Relationship Between Communication Competence. Job Performance and Supervisory Roles. Journal of Leadership and Orgabizational Studies, Vol.11 No. 2

Rahma, Khairiah (2012). Perbedaan Kompetensi Komunikasi Antara Remaja Awal Bilingual dengan Monolingual. Available FTP: http://repository.usu.ac.id/handle/123456789/30841.pdf. 
Ria, E., Asriani Abbas, A., Hasyim, M. 2020. Efektivitas Model Direct Instruction dalam Meningkatkan Kemampuan Siswa SMA Negeri 1 Batauga Memahami Nilai dalam Folklore Wandiudiu. Jurnal Ilmu Budaya, Volume 8, Nomor 1, Juni 2020, pp. 159-171

Rickheit, G. dan Strohner, H. (2008). Handbook Of Communication Competence. Berlin: Mouton de Gruyter.

Ruben, Brent D. \& Stewart, Lea P. (2006). Communication and Human Behaviour. USA: Alyn and Bacon.

Salleh, L.M. (2006). Communication Competence : A Malaysian Perspective. Journal of Human Communication Vol.11 No. 3,pp. 303-312 [on-line series]. Available. FTP:

www.uab.edu/Communicationstudies/humancommunication/11.3.0 4.pdf

Saputra, W.I., Hasyim, M.,G. Junus, F.G. 2020. Perspektif Media Prancis dalam Pemberitaan Pencemaran Air di Indonesia. Al-Munzir, 13.(1), 34.

Soler, Eva. A. dan Jorda, Maria P.S. (2007). Intercultural Languange Use and Languange Learning. Netherlands: Springer.

Sugiyono, P. D. (2015). Metode Penelitian Kuantitatiif, Kualitatif dan R\&D. Bandung: Alfabeta.

Sugiyono, P. D. (2016). Metode Penelitian Kuantitatiif, Kualitatif dan R\&D. Bandung: Alfabeta.

Supardi (2014). Aplikasi Statistika Dalam Pendidikan. Jakarta: Change Publication.

Purhantara, Wahyu (2010). Metode Penelitian Kualitatif Untuk Bisnis. Yogyakarta: Graha Ilmu.

Widiasworo, Erwin (2018). Cerdas Pengelolaan Kelas. Yogyakarta: DIVA Press. Sudrajat, Ahmad (2012). Aspek dan Indikator Kompetensi Pedagogik Pengajar Journal. Available FTP : 
https://akhmadsudrajat.wordpress.com/2012/01/29/kompetensi-pedagogikpengajar

Sapoetra, Jimmy (2017). Kompetensi Pedagogik. Available FTP : https:// https://pgsd.binus.ac.id/2017/12/31/kompetensi-pedagogik 